\title{
Para conhecer e degustar: uma análise dos atrativos gastronômicos de São Paulo através do Guia da Cidade
}

To know and taste: an analysis of the gastronomic attractions of São Paulo through the City Guide

\section{Maria Henriqueta Sperandio Garcia Gimenes-Minasse}

Universidade Anhembi Morumbi - UAM - São Paulo - São Paulo - Brasil

\begin{abstract}
$\longrightarrow$
Resumo: Este artigo desenvolve, através uma pesquisa bibliográfica e documental, uma análise dos atrativos gastronômicos da cidade de São Paulo mencionados na publicação oficial Guia da Cidade. A partir de princípios da análise de conteúdo, identifica-se quais são as menções sobre o universo gastronômico e analisa-se as menções relacionadas aos atrativos, identificando sua tipologia e descrição. Como principais resultados destacam-se: o Guia realiza várias menções a elementos gastronômicos; a imagem gastronômica da cidade é marcada pelas ideias de diversidade e dinamicidade; os principais atrativos gastronômicos indicados são o conjunto de bares, restaurantes e similares e o Mercado Municipal.
\end{abstract}

Palavras-chave: Turismo gastronômico. Atrativo Gastronômico. São Paulo (SP).

\begin{abstract}
This article develops, through a bibliographical and documentary research, an analysis of the gastronomic attractions of the city of São Paulo mentioned in the official publication Guia da Cidade. Based on the principles of content analysis, it identifies the mentions about the gastronomic universe and analyzes them in relation to gastronomic attractions, identifying their typology and description. As main results stands out: the Guide makes several mentions to gastronomic elements; the gastronomic image of the city is marked by the ideas of diversity and dynamicity; the main gastronomic attractions indicated are the set of bars, restaurants and similar and the Municipal Market.
\end{abstract}

Keywords: Food Tourism. Gastronomic attractions. São Paulo (SP). 


\section{Introdução}

A alimentação, suas práticas e serviços possuem uma grande importância no contexto da oferta turística: constituem tanto um serviço indispensável para o desenvolvimento da atividade (encaixando-se na categoria de equipamentos e serviços turísticos) quanto podem exercer a capacidade de gerar interesse e fluxos de visitação (caracterizando-se assim como atrativo turístico). Seja como atrativo ou como um elemento integrador da experiência turística, muitos destinos têm investido na gastronomia como um produto de diferenciação (Richards, 2002; Hall; Sharples, 2003) e este movimento pode ser observado inclusive no Brasil.

A cidade de São Paulo atende, apesar de alguma polêmica, pelo epíteto de 'Capital Mundial da Gastronomia' (ABRESI, 2017) e é sem dúvida uma das grandes referências nacionais no segmento da alimentação fora do lar. Segundo a ABRASEL Associação Brasileira de Bares, Restaurantes e Similares (2017), a cidade conta com aproximadamente 55 mil estabelecimentos, sediando restaurantes internacionalmente renomados (como o D.O.M. do chef Alex Atala e o Maní da chef Helena Rizzo), filiais de importantes restaurantes internacionais (incluindo desde o Empório e Restaurantes Eataly do chef italiano Massimo Bottura até o La Mar Cebicheria do premiado chef peruano Gastón Acúrio) e divide, junto com a cidade do Rio de Janeiro, o protagonismo do Guia Michelin, tendo 1 restaurante agraciado com 2 estrelas e 12 restaurantes com 01 estrela na edição de 2017 (GUIA MICHELIN, 2017).

Do ponto de vista turístico, São Paulo também se destaca. Dados divulgados pelo último anuário publicado pelo Observatório de Turismo (2015) indicam que a cidade recebeu aproximadamente 15 milhões de visitantes (540 mil apenas durante a Copa do Mundo FIFA 2014), gerando uma receita para a capital de cerca de $R \$ 11,3$ bilhões. A arrecadação de ISS do pelo turismo teve valor de $\mathrm{R} \$ 270,8$ milhões, equivalente à $2,5 \%$ dos $\mathrm{R} \$ 10,8$ bilhões gerados em tributos por todas as atividades econômicas na cidade de São Paulo, um crescimento de $7,3 \%$ se comparado aos valores de 2013.

A expressividade da atividade turística na cidade impacta diretamente nos negócios gastronômicos. Turistas e excursionistas tendem a utilizar os estabelecimentos de alimentos e bebidas das localidades visitadas para realizar todas as suas refeições, incentivando, desta forma, economicamente o segmento. Contudo, estes dados não permitem perceber se a alimentação - suas manifestações e estabelecimentos vinculados - se constituem como elemento de interesse destes visitantes. Este questionamento, que exigira uma pesquisa de demanda para ser respondida, fomentou o surgimento de uma outra indagação: a cidade de São Paulo trabalha turisticamente uma imagem gastronômica? Como primeira iniciativa sistematizada para responder a essa pergunta, decidiu-se identificar e analisar os elementos gastronômicos mencionados nos materiais de divulgação elaborados pela São Paulo Turismo (também conhecida como São Paulo Turismo ou SP Turis), órgão oficial de turismo da cidade.

Embora não se caracterize como uma análise de conteúdo propriamente dita, o estudo aqui realizado seguiu alguns princípios propostos por Bardin (2006). Para este autor a análise de conteúdo exige uma etapa preliminar, na qual o pesquisador estabelece contato com os documentos, escolhe qual (ou quais) documento será objeto de análise, formula hipóteses e objetivos e elabora os indicadores que orientarão os trabalhos (Bardin, 2006). Neste sentido, na etapa de pré-análise realizou-se uma 'leitura flutuante' das 29 publicações promocionais que a SPTuris disponibiliza em pdf on line (e que também estão disponíveis nas versões impressas nos Centros de Informação Turística da cidade) apresentadas no quadro 1. 
QUADRO 1 - Publicações promocionais institucionais da Cidade de São Paulo

\begin{tabular}{|c|c|c|}
\hline & Publicação & Características \\
\hline 1 & $\begin{array}{l}\text { Acontece em } \\
\text { São Paulo }\end{array}$ & $\begin{array}{l}\text { Publicação mensal sobre os } \\
\text { eventos da cidade. }\end{array}$ \\
\hline 2 & $\begin{array}{l}\text { Fique mais } \\
\text { um dia }\end{array}$ & $\begin{array}{l}\text { Guia que apresenta passeios que } \\
\text { podem ser realizados em apenas } \\
\text { um dia, com o objetivo de } \\
\text { aumentar a permanência do } \\
\text { visitante na cidade. }\end{array}$ \\
\hline 3 & $\begin{array}{l}\text { Guia da } \\
\text { cidade }\end{array}$ & $\begin{array}{l}\text { Guia turístico que apresenta } \\
\text { informações gerais sobre a cidade } \\
\text { e seus principais atrativos } \\
\text { turísticos. }\end{array}$ \\
\hline 4 & $\begin{array}{l}\text { Guia } \\
\text { profissionais } \\
\text { do Turismo }\end{array}$ & $\begin{array}{l}\text { Manual MICE e Turismo de Lazer: } \\
\text { publicações que apresentam } \\
\text { informações destinadas aos } \\
\text { profissionais de turismo. }\end{array}$ \\
\hline 5 & Mapas & $\begin{array}{l}\text { Conjunto de } 8 \text { mapas: Centro; } \\
\text { Geral; Ipiranga; Mapa das } \\
\text { sensações; Morumbi; Paulista; } \\
\text { Pinheiros; Santana. }\end{array}$ \\
\hline 6 & $\begin{array}{l}\text { Série Roteiros } \\
\text { Temáticos }\end{array}$ & $\begin{array}{l}\text { Conjunto de } 14 \text { publicações que } \\
\text { abordam diferentes temáticas } \\
\text { pela cidade. São elas: Afro; Arte } \\
\text { urbana; Arquitetura pelo Centro; } \\
\text { Cidade Criativa; Faces; Futebol, } \\
\text { Geek; Guia GLBT; Independência } \\
\text { do Brasil; Mirantes; O café a e } \\
\text { história da cidade; Polo de } \\
\text { Ecoturismo; Turismo no Centro; } \\
\text { Zona Leste. }\end{array}$ \\
\hline 7 & $\begin{array}{l}\text { SP } \\
\text { Experience }\end{array}$ & $\begin{array}{l}\text { Publicação que apresenta os } \\
\text { principais atrativos da cidade } \\
\text { organizados a partir dos } 5 \\
\text { sentidos humanos. }\end{array}$ \\
\hline 8 & $\begin{array}{l}\text { Viva Tudo } \\
\text { Isso }\end{array}$ & $\begin{array}{l}\text { Publicação que apresenta os } \\
\text { principais atrativos da cidade de } \\
\text { São Paulo. Trata-se de uma } \\
\text { síntese do Guia da Cidade. }\end{array}$ \\
\hline
\end{tabular}

Fonte: SPTURIS (2017).

A partir desta leitura realizou-se a seleção de quais documentos iriam compor o escopo de análise, sendo escolhido o 'Guia da Cidade', uma publicação de 2015 com 166 páginas que apresenta as principais características da cidade e divulga, de forma atraente em um texto bilíngue (português e inglês) os principais atrativos locais. Esta publicação tem características de um guia turístico, e ao apresentar as diferentes facetas de São Paulo, oferece um material que permite vislumbrar um esforço de formação de uma imagem do local.] Foram estabelecidos então os seguintes objetivos: identificar quais são as menções relacionadas ao universo gastronômico (tais como estabelecimentos comerciais, acontecimentos programados, feiras e práticas alimentares); quais destas representam atrativos turísticos; de que forma são descritas e a que tipologia de atrativos gastronômicos pertencem. Para alcançar estes objetivos a etapa de exploração do material se concentrou na decomposição do texto tendo como referência as unidades de análise estabelecidas e a construção de quadros-sínteses, parcialmente apresentados aqui. Posteriormente foi realizado o tratamento dos resultados com a interpretação e construção da análise propriamente dita, momento em que utilizou-se a elaboração de word clouds (nuvens de palavras) para uma melhor visualização dos termos mais referenciados. Esperase, desta forma, conseguir vislumbrar, mesmo que de maneira preliminar, os elementos que compõem a imagem gastronômica da cidade de São Paulo.

\section{0 papel dos guias na formação da imagem de um destino}

Alhemoud e Armstrong (1996) observam que o termo imagem turística pode incorporar diferentes significados, podendo ser descrito como o conjunto de ideias ou conceitos que um indivíduo ou grupo constrói em relação a um destino turístico. Como destacam Cooper et al (2001), uma imagem - seja ela positiva ou negativa - desempenha um importante papel na tomada de decisão sobre qual destino visitar, sendo também crucial para estabelecer os parâmetros que orientarão o julgamento de satisfação do visitante. Contudo, a formação de uma imagem é um processo complexo, que envolve a percepção de atributos objetivos e subjetivos e podem ser construídos a partir de diferentes fontes de informação, como livros, filmes, guias turísticos, material publicitário institucional, experiência pessoal e de conhecidos (Cooper et al, 2001).

Os guias turísticos tendem a ser percebidos como uma leitura funcional, de caráter utilitário, na medida em que descrevem e apresentam uma realidade. Contudo, como observa De Morais (2012, p.324), esta visão simplificada deve ser evitada, já que "[...] os guias impressos podem revelar a rede de variáveis implícitas na dinâmica da atividade; as suas diversas configurações ao longo da história e suas 
relações com os contornos mais gerais dos grupos sociais". Para Matos e Santos (2004), os guias impressos são resultado de uma construção histórica e expressam uma percepção de mundo a partir de suas descrições, eleições e indicações.

Deve-se ter clareza de que, ao eleger o que deve ou não ser conhecido, um guia turístico visa otimizar os recursos de tempo e dinheiro de seu usuário. Porém, neste processo, elementos ganham destaque e outros são omitidos, construindo e transmitindo um conjunto de percepções para o leitor. A realidade desta forma nunca é somente descrita, é também traduzida, decodificada, criando um conjunto de imagens que terminam por caracterizar um destino.

Csergo (1998) enfatiza o papel dos guias turísticos - em conjunto com os livros de receita - na construção do imaginário das cozinhas regionais na França, ressaltando que ao apontar uma especialidade gastronômica como elemento de destaque de uma localidade a coloca no mesmo patamar de outros atrativos turísticos, distinguindo-a como algo que merece ser conhecido (e, no caso específico, degustado). E, neste processo, ao enaltecer algumas iguarias e deixar de mencionar outras, a própria ideia de uma tipicidade gastronômica começa a ser definida.

Observa-se que o próprio Guia Michelin, citado no início deste artigo, nasceu como um guia turístico e apenas posteriormente foi desmembrado também em guia gastronômico, e tornou-se uma publicação de referência no contexto gastronômico internacional, tendo a sua classificação de estabelecimentos reconhecida mundialmente como parâmetro de qualidade.

Destaca-se que o objeto de análise deste artigo - o Guia da Cidade (SPTuris, 2015) - é um documento oficial, e, portanto, reproduz uma imagem pensada institucionalmente. É apresentado no formato de um Guia, sendo constituído por dados informativos, mas é também uma forma de propaganda institucional, vinculada a um discurso de cidade. Ao descrever São Paulo e seus recantos, selecionar e caracterizar atrativos, este material busca estabelecer uma ideia específica de cidade e direcionar os olhos do visitante para os elementos que validam essa construção.

\section{Atrativos gastronômicos: definição e características}

Como já observado, a gastronomia e os serviços a ela relacionados podem integrar a oferta turística de uma localidade sob diferentes configurações. Para Lohmann e Panosso Netto (2008) a oferta turística pode ser entendida como todos os bens e serviços que estão à disposição dos consumidores-turistas, por um dado preço em um determinado período de tempo. Suas três categorias integradoras são: atrativos turísticos; serviços e equipamentos turísticos; e infraestrutura de apoio turístico.

Os atrativos turísticos podem ser entendidos como todo lugar, objeto ou acontecimento de interesse turístico que motiva o deslocamento de grupos humanos para conhecê-los, podendo ser naturais, histórico-culturais; manifestações e usos tradicionais e populares; realizações técnicas e científicas contemporâneas; acontecimentos programados (Lohmann; Netto, 2008). Nota-se que vários elementos gastronômicos podem desempenhar o papel de um atrativo turístico, independente de qual seja a vocação turística prevalecente em uma localidade.

Notabilizados como serviços fundamentais para a permanência do visitante em uma localidade, estabelecimentos e serviços de alimentação - assim como outras manifestações gastronômicas - podem se tornar atrativos turísticos. Para Gimenes-Minasse (2014, p.4), um atrativo turístico é:

[...] é todo lugar, iguaria (comida e bebida), modo de preparo, produção ou serviço, acontecimento programado, estabelecimento destinado ao serviço de alimentação fora de casa ou qualquer outro empreendimento vinculado à alimentação que tenha interesse turístico e gere deslocamentos de grupos humanos com o objetivo de conhecê-lo. 
Esta definição indica as amplas possibilidades de aproveitamento turístico de elementos gastronômicos. Schlüter (2006), por sua vez, indica as seguintes categorias de atrativos turísticos gastronômicos: os cenários gastronômicos, as festas e os festivais, e as rotas gastronômicas. Os cenários gastronômicos são lugares onde se produz a interação social a partir da comida e da bebida e são subdivididos entre públicos (restaurantes, cafés, bares, etc...) e privados (refeitórios nos centros urbanos, cozinhas no campo, etc). As festas e festivais são, por sua vez, acontecimentos programados em que elementos gastronômicos tem grande relevância e que se subdividem em: ecofestas; teológicas; seculares; privadas. As rotas turísticas são iniciativas que "[...] permitem integrar em um produto os elementos que individualmente não atraem interesse suficiente ou contam com certas dificuldades de promoção ou comercialização, tornando possível um produto final de maior valor [...]" (Schlüter, 2006, p. 71) e podem ser organizadas em função de um produto ou um traço cultural característico.

Para Gândara et al (2009), o turismo gastronômico pode ser operacionalizado a partir de atrativos como culinária regional, eventos gastronômicos e oferta de estabelecimentos de alimentos e bebidas diferenciados, bem como roteiros, rotas e circuitos gastronômicos. Já Fagliari (2005) destaca, como atrativos turísticos gastronômicos, bares e restaurantes; pratos e produtos típicos; locais de produção; lojas e mercados; eventos; rotas gastronômicas; e outros elementos (tais como escolas de culinária, museus, passeios de trem associados à degustação). Gimenes-Minasse (ANPTUR, 2014, p.7) indica, a partir de Fagliari (2005) e Schlüter (2006), seis categorias de atrativos gastronômicos, apresentadas no quadro 2:

\section{QUADRO 2 - Categorias de atrativos gastronômicos}

\begin{tabular}{|c|l|llr|}
\hline & Categoria & Integrantes & \\
\hline 1 & $\begin{array}{l}\text { Estabelecimentos } \\
\text { de alimentação }\end{array}$ & $\begin{array}{l}\text { Bares, restaurantes, casas } \\
\text { noturnas, padarias e outros }\end{array}$ \\
\hline
\end{tabular}

\begin{tabular}{|c|c|c|}
\hline & fora do lar & $\begin{array}{l}\text { estabelecimentos } \\
\text { alimentação fora do lar que } \\
\text { possam gerar interesse turístico. }\end{array}$ \\
\hline 2 & $\begin{array}{l}\text { Pratos e produtos } \\
\text { típicos }\end{array}$ & $\begin{array}{l}\text { Pratos e produtos típicos } \\
\text { pertencentes à gastronomia } \\
\text { local e regional. }\end{array}$ \\
\hline 3 & $\begin{array}{l}\text { Locais de } \\
\text { produção } \\
\text { alimentar }\end{array}$ & $\begin{array}{l}\text { Espaços de produção alimentar } \\
\text { tais como queijarias, vinícolas, } \\
\text { chocolaterias, alambiques, etc, } \\
\text { que estejam preparados para } \\
\text { visitação. }\end{array}$ \\
\hline 4 & $\begin{array}{l}\text { Estabelecimentos } \\
\text { de } \\
\text { comercialização } \\
\text { de produtos }\end{array}$ & $\begin{array}{l}\text { Locais cuja atividade principal é } \\
\text { a venda de produtos } \\
\text { alimentícios, tais como } \\
\text { mercados municipais, adegas, } \\
\text { lojas de chocolate, etc. É } \\
\text { possível que raja } \\
\text { comercialização de alimentos } \\
\text { prontos para o consumo, mas } \\
\text { este não é o cerne da atividade } \\
\text { local. }\end{array}$ \\
\hline 5 & $\begin{array}{l}\text { Feiras livres, } \\
\text { feiras } \\
\text { gastronômicas e } \\
\text { comida de rua }\end{array}$ & $\begin{array}{l}\text { Feiras realizadas em praças e } \\
\text { ruas da cidade, com a finalidade } \\
\text { de comercialização de produtos } \\
\text { in natura ou em estado de } \\
\text { semiprocessamento artesanal } \\
\text { (feiras livres); ou especializadas } \\
\text { em comida e bebida pronta para } \\
\text { consumo (feiras gastronômicas); } \\
\text { A menção à 'comida de rua' } \\
\text { inclui barracas e foodtrucks que } \\
\text { oferecem alimentos e bebidas } \\
\text { prontos para o consumo em } \\
\text { locais públicos, sem se } \\
\text { constituírem, por definição, em } \\
\text { um restaurante, bar ou similar. }\end{array}$ \\
\hline 6 & $\begin{array}{l}\text { S } \\
\text { hômicos }\end{array}$ & $\begin{array}{l}\text { Acontecimentos programados } \\
\text { cuja centralidade da atração } \\
\text { reside na comida, na bebida e } \\
\text { nas práticas e rituais a ela } \\
\text { relacionadas. }\end{array}$ \\
\hline 7 & $\begin{array}{l}\text { Roteiros, rotas e } \\
\text { circuitos } \\
\text { gastronômicos }\end{array}$ & $\begin{array}{l}\text { Roteiros, rotas e circuitos que } \\
\text { tenham temática abertamente } \\
\text { gastronômica, ou que possuam } \\
\text { uma alta incidência de } \\
\text { elementos gastronômicos dentre } \\
\text { seus atrativos. }\end{array}$ \\
\hline 8 & Outros & $\begin{array}{l}\text { Escolas de culinária, espaços } \\
\text { culturais com serviços de } \\
\text { alimentação difenciados, } \\
\text { museus sobre alimentação, } \\
\text { outros atrativos associados à } \\
\text { comida e à bebida e que não } \\
\text { estejam contemplados nas } \\
\text { categorias anteriores. }\end{array}$ \\
\hline
\end{tabular}

Fonte: Gimenes-Minasse (2014, p. 7).

Deve-se considerar que muitas vezes estes elementos não possuem atratividade suficiente para gerar fluxos turísticos por si só, mas considera-se que os mesmos podem ser importantes para a complementação, a diferenciação e o aumento de competitividade de um destino, independente de sua vocação turística mais evidente. É preciso observar, porém, que os interesses dos visitantes podem variar 
em relação aos elementos gastronômicos da localidade visitada.

Em relação a este aspecto, Hall e Sharples (2003) propõem quatro categorias relativas ao grau de interesse do visitante em relação às práticas alimentares de um destino: na primeira, os atrativos gastronômicos são motivação primária e as atividades no destino são, majoritavelmente, relacionadas à comida. $\mathrm{Na}$ segunda categoria, os atrativos gastronômicos compõem com alguma importância a escolha do destino; na terceira, os visitantes possuem baixo interesse em gastronomia e buscam atrativos gastronômicos apenas por considerá-los diferentes. E na quarta e última categoria constam os visitantes que possuem nenhum ou pouco interesse em gastronomia, que frequentam bares, restaurantes e similares porque precisam satisfazer uma necessidade fisiológica. Neste caso, os elementos gastronômicos são vistos apenas como um serviço indispensável para a permanência do visitante no local.

Ao definirem o segmento, Richards (2002) e Hall e Sharples (2003) observam a importância da distinção entre turistas que consomem comida como uma parte da experiência de viagens e turistas cujas atividades, comportamentos e até mesmo as decisões sobre a seleção de destinos é influenciada pelo interesse em comida e bebida. Observa-se que, na perspectiva da conceituação de turismo gastronômico o interesse pelas práticas alimentares deve desempenhar um papel de protagonismo.

O turismo gastronômico é definido por Hall e Sharples (2003, p.10) como aquele em que a "[...] visitation to primary and secondary food producers, food festivals, restaurants and specific locations for which food tasting and/or experiecing the attributes of specialist food production region are the primary motivating factor for travel". Por consequência, não basta que o turista vá a um determinado restaurante ou deseje provar uma comida ou ingrediente produzido em uma determinada localidade, é preciso que as práticas alimentares tenham fator de grande relevância no momento de se decidir para onde ir e o que fazer na localidade escolhida.
Fagliari (2005) constrói sua definição de turismo gastronômico separando o viés da demanda turística do da oferta. Para a autora, sob a perspectiva da demanda turística, o turismo gastronômico consiste em toda viagem na qual a motivação principal está no prazer em degustar alimentos e bebidas e conhecer elementos gastronômicos de uma localidade. Sob a perspectiva da oferta turística, esta atividade se caracteriza pela oferta e promoção de elementos gastronômicos como atrativos turísticos como principais do destino. A definição de Gandara et al (2009, p. 181), por sua vez, dá ênfase ao entendimento da comida e da bebida como uma prática cultural. Para estes autores o turismo gastronômico é: "[...] uma vertente do turismo cultural no qual o deslocamento de visitantes se dá por motivos vinculados às práticas gastronômicas de uma determinada localidade".

\section{O objeto de estudo - Guia da Cidade}

Como já mencionado, o Guia da Cidade é uma publicação de divulgação oficial organizada como um guia turístico. A estrutura do documento é apresentada no Quadro 3:

\section{QUADRO 3 - Estrutura do Guia da Cidade}

\begin{tabular}{|l|l|l|}
\hline & Item & Breve descritivo \\
\hline 1 & $\begin{array}{l}\text { Viva tudo } \\
\text { isso }\end{array}$ & $\begin{array}{l}\text { É realizada uma apresentação geral } \\
\text { da cidade de São Paulo. Aspectos } \\
\text { relacionados ao entretenimento, à } \\
\text { cultura, à vida noturna, às compras e } \\
\text { à gastronomia são ressaltados. }\end{array}$ \\
\hline 2 & $\begin{array}{l}\text { Atrações } \\
\text { imperdíveis }\end{array}$ & $\begin{array}{l}\text { São indicadas 11 atrações } \\
\text { imperdíveis da cidade de São Paulo. }\end{array}$ \\
\hline 3 & $\begin{array}{l}\text { São Paulo } \\
\text { por regiões }\end{array}$ & $\begin{array}{l}\text { São apresentadas oito regiões da } \\
\text { cidade (Paulista e Jardins; Centro; } \\
\text { Vila Mariana e Ipiranga; Morumbi e } \\
\text { Butantã; Santana, Pacaembu e } \\
\text { Higienópolis; Pinheiros e Vila } \\
\text { Madalena; Zona Leste; Pólo de } \\
\text { Ecoturismo) são apresentadas a } \\
\text { partir de uma caracterização geral e } \\
\text { da indicação de seus principais } \\
\text { atrativos. }\end{array}$ \\
\hline 4 & $\begin{array}{l}\text { São apresentadas informações sobre } \\
\text { fuso horário, clima, moeda, horário } \\
\text { comercial, saúde, mobilidade } \\
\text { (bicicletas, ônibus, metrô, trem, } \\
\text { rodoviárias, táxi, carro e aeroportos), } \\
\text { telefones (ligações intermunicipais e } \\
\text { serviços }\end{array}$ \\
& $\begin{array}{l}\text { interestaduais, ligações } \\
\text { telefones acionais, cartões telefônicos,, } \\
\text { segurança, }\end{array}$ \\
\hline
\end{tabular}




\begin{tabular}{|c|l|l|}
\hline & & $\begin{array}{l}\text { hospedagem, serviços de receptivo e } \\
\text { walking tours. }\end{array}$ \\
\hline 5 & $\begin{array}{l}\text { Calendário } \\
\text { de eventos }\end{array}$ & $\begin{array}{l}\text { São destacados os principais eventos } \\
\text { da cidade e apresentados todos os } \\
\text { que ocorrerão na cidade naquele ano, } \\
\text { distribuídos por meses. }\end{array}$ \\
\hline 6 & $\begin{array}{l}\text { CITs - } \\
\text { Centrais de } \\
\text { Informação } \\
\text { Turística }\end{array}$ & $\begin{array}{l}\text { São indicados os endereços das 7 } \\
\text { CIT's da cidade, com a indicação da } \\
\text { estação de metrô mais próxima. }\end{array}$ \\
\hline 7 & $\begin{array}{l}\text { São Paulo à } \\
\text { pé }\end{array}$ & $\begin{array}{l}\text { São mencionados 11 roteiros } \\
\text { sugeridos pela SPTuris (Arquitetura } \\
\text { pelo Centro Histórico, Afro, } \\
\text { Independência do Brasil, Mirantes, } \\
\text { Ecorrural, Futebol, Arte Urbana, } \\
\text { Cidade Criativa, O Café e a História } \\
\text { da Cidade, Geek e Zona Leste) com } \\
\text { indicação de como obter o download } \\
\text { do material. .Os roteiros não são } \\
\text { especificados. }\end{array}$ \\
\hline
\end{tabular}

Fonte: o autor baseado em SPTURIS (2015).

Os itens 'Informações úteis e serviços', 'CITs Centrais de Informação Turística' e 'São Paulo à pé' não realizam menção direta a elementos gastronômicos. O item 'Calendário de eventos' foi desconsiderado por não ser possível constatar se as informações ainda eram compatíveis com a realidade. Os demais itens serão analisados na sequência.

A primeira página do item "Viva tudo isso" apresenta o objetivo da publicação, ressaltando seu aspecto utilitário e o apelo prático de seu uso: "este guia foi pensado para facilitar a sua vida, elencando os pontos turísticos mais visitados, os serviços para aproveitar o melhor de São Paulo, dicas de aplicativos que auxiliam a estadia, além do calendário de eventos e outras informações úteis" (SPTuris, 2015, p.3). Na sequência, há uma apresentação sucinta da cidade:

Com uma população formada por quase 12 milhões de habitantes, de 70 diferentes nacionalidades, e ainda com mais de 15 milhões de turistas recebidos ao ano, São Paulo é uma cidade global que une costumes e culturas. Absolutamente diversa, São Paulo é antenada, geradora de tendências e estilos, com opções de lazer, negócios e entretenimento para as mais diversas tribos: de intelectuais a esportistas, passando por baladeiros, religiosos, moderninhos e workaholics. Como não podia deixar de ser, esta diversidade também se reflete em todos os tipos de arte, assim como na moda. Aqui, você pode encontrar desde engravatados andando apressados pela Avenida Paulista até jovens cosplayers passeando pelo shopping. Conhecida por sua versatilidade, São Paulo surpreende em todos os sentidos. Você pode fazer um passeio de bicicleta, conhecer um dos famosos e inúmeros shopping centers ou degustar a variada gastronomia - tudo num só dia (SPTURIS, 2015. p.3) [grifo nosso]

Em uma linguagem bastante coloquial permeada por neologismos, São Paulo é associada a atributos que evidenciam sua diversidade (diferentes nacionalidades; união de costumes e culturas; com diferentes opções de lazer, negócios e entretenimento para as mais diversas tribos; diversa; todos os tipos de arte; versatilidade; variada gastronomia) e dinamicidade (antenada; geradora de tendências e estilos; surpreende em todos os sentidos), observando-se também uma menção explícita à questão gastronômica (ou degustar a variada gastronomia).

Este item coloca em evidência os seguintes aspectos: vida noturna, compras e gastronomia. 0 quadro 4 apresenta as menções à gastronomia observada em cada um destes subitens:

\section{QUADRO 4 - Conteúdo do item 'Viva tudo isso'}

\begin{tabular}{|c|c|c|}
\hline & Destaques & Menções à gastronomia \\
\hline 1 & Vida noturna & $\begin{array}{l}\text { A vida noturna em São Paulo é um } \\
\text { retrato fiel da cidade: frenética, } \\
\text { criativa e democrática. [...] Alguns } \\
\text { bairros, por possuirem grande } \\
\text { concentração de bares e casas } \\
\text { noturnas, são destinos certos para } \\
\text { quem quer curtir a noite. Vila } \\
\text { Madalena, Itaim Bibi, Vila Olímpia e } \\
\text { Jardins estão entre as opções mais } \\
\text { tradicionais. Outros como Barra } \\
\text { Funda e o Centro da cidade } \\
\text { concentram muitas baladas e bares } \\
\text { alternativos (p.11). }\end{array}$ \\
\hline 2 & Compras & $\begin{array}{l}\text { Menciona a variada } \\
\text { gastronômica dos mais de } 50 \\
\text { shoppings da cidade (p.12). }\end{array}$ \\
\hline 3 & Gastronomia & $\begin{array}{l}\text { A Gastronomia riquíssima e } \\
\text { diversificada. Isso é o que se } \\
\text { encontra em São Paulo. A cidade } \\
\text { reúne alguns dos melhores } \\
\text { restaurantes da América Latina e do } \\
\text { mundo, como o D.O.M., de Alex } \\
\text { Atala, o o Maní, de Helena Rizzo, } \\
\text { eleita a melhor chef mulher do } \\
\text { mundo (prêmio da revista } \\
\text { Restaurant, 2014). São mais de } 15 \\
\text { mil restaurantes e } 20 \text { mil bares que } \\
\text { oferecem os mais variados tipos de } \\
\text { culinária, com opções nacionais e } \\
\text { internacionais e que atendem a todos } \\
\text { os bolsos. Além disso, São Paulo } \\
\text { tem uma culinária própria, } \\
\text { oferecendo desde coxinha de siri a }\end{array}$ \\
\hline
\end{tabular}




\begin{tabular}{|l|l|}
\hline & $\begin{array}{l}\text { brigadeiro de capim santo. A } \\
\text { metrópole também é conhecida pela } \\
\text { comida de rua e pelas famosas } \\
\text { "Feirinhas Gastronômicas", que } \\
\text { atraem milhares de paulistanos e } \\
\text { turistas. (p.14) }\end{array}$ \\
\hline
\end{tabular}

Fonte: 0 autor baseado em SP TURIS (2015).

Os atributos de diversidade e dinamicidade, evidentes na apresentação da cidade de São Paulo, também estão presentes no descritivo de "vida noturna" e "gastronomia". A vida noturna é caracterizada como um 'retrato fiel da cidade', 'frenética', 'criativa', 'democrática', com espaço para estabelecimentos 'mais tradicionais' e 'alternativos'. A gastronomia é caracterizada como 'riquíssima' e 'diversificada', sendo seus elementos de destaque 'melhores restaurantes', 'variados tipos de culinária', 'opções nacionais e internacionais', '[opções] que atendem a todos os bolsos', 'culinária própria', 'comida de rua', 'famosas Feirinhas Gastronômicas'. Merecem menções nominais o restaurante D.O.M. de Alex Atala, o restaurante Maní, de Helena Rizzo e as iguarias 'coxinha de siri' e 'brigadeiro de capim santo'. O item compras apenas menciona a oferta gastronômica presente nos shoppings centers, uma menção que se relaciona mais com a ideia de serviço indispensável do que a de um atrativo turístico.

O item 'Atrações imperdíveis' apresenta de forma sintética as 11 atrações imperdíveis, mencionado quatro atrações que recebem menção à gastronomia, conforme evidencia o quadro 5 :

QUADRO 5 - Conteúdo do item 'Atrativos Imperdíveis'

\begin{tabular}{|l|l|l|}
\hline & Atração & Menções à Gastronomia \\
\hline 1 & $\begin{array}{l}\text { Avenida } \\
\text { Paulista }\end{array}$ & $\begin{array}{l}\text { Indica "várias opções de lojas e } \\
\text { restaurantes" (p.21). }\end{array}$ \\
\hline 2 & $\begin{array}{l}\text { Bairro da } \\
\text { Liberdade }\end{array}$ & $\begin{array}{l}\text { "Entre as atrações estão restaurantes e } \\
\text { docerias típicas, além de lojas de } \\
\text { produtos orientais e livrarias. Festas } \\
\text { como o Ano Novo Chinês, Hanamatsuri } \\
\text { (Festival das Flores), Tanabata Matsuri } \\
\text { (Festival das Estrelas), entre outros, } \\
\text { animam as ruas do bairro" (p.25). }\end{array}$ \\
\hline 3 & $\begin{array}{l}\text { Mercado } \\
\text { Municipal dos maiores centros de } \\
\text { abastecimento da cidade, é famoso por } \\
\text { possuir uma grande diversidade de } \\
\text { frutas e legumes, além de outros tipos } \\
\text { de mercadorias como queijos, } \\
\text { temperos, frutos do mar, carnes } \\
\text { exóticas e vinhos. O prédio, com vitrais } \\
\text { e um estilo arquitetônico que encanta, é }\end{array}$ \\
\hline
\end{tabular}

\begin{tabular}{|c|c|c|}
\hline & & $\begin{array}{l}\text { um ótimo local para um lanche ou } \\
\text { almoço. No mezanino há restaurantes } \\
\text { com deliciosos quitutes, sendo os mais } \\
\text { famosos o sanduíche de mortadela e o } \\
\text { pastel de bacalhau. O Mercadão, como } \\
\text { é chamado, fica localizado próximo à } \\
\text { rua } 25 \text { de Março" (p.31). }\end{array}$ \\
\hline 4 & $\begin{array}{l}\text { Vila } \\
\text { Madalena }\end{array}$ & $\begin{array}{l}\text { "Reduto dos boêmios de plantão, a Vila } \\
\text { Madalena inspira descontração e arte. } \\
\text { Durante o dia o movimento acontece } \\
\text { nas livrarias, cafés e outros cantinhos } \\
\text { para compras descoladas, além de } \\
\text { ateliês e galerias de arte renomadas } \\
\text { como a Choque Cultural e a Fortes } \\
\text { Vilaça. Restaurantes despojados tornam } \\
\text { o passeio por aqui ainda mais } \\
\text { agradável, em geral trazendo um } \\
\text { tempero bem brasileiro para a refeição. } \\
\text { Em suas ruas, bares e casas noturnas } \\
\text { para todos os gostos são facilmente } \\
\text { encontrados, e a qualquer hora é } \\
\text { possível ver suas mesas com turmas } \\
\text { animadas se divertindo" (p.31). }\end{array}$ \\
\hline
\end{tabular}
Fonte: O autor baseado em SP TURIS (2015).

O único atrativo gastronômico destacado isoladamente é o Mercado Municipal, caracterizado por seu tamanho ('um dos maiores centros de abastecimento da cidade'), pela 'grande diversidade de frutas e legumes, além de outros tipos de mercadoria' e pelo sabor de seus 'deliciosos quitutes'. O aspecto arquitetônico também é evidenciado, assim como as iguarias 'sanduíche de mortadela' e 'pastel de bacalhau'.

\section{A Avenida Paulista e a Vila Madalena se} colocam em evidência pela concentração de estabelecimentos. A Vila Madalena é apresentada como um 'reduto de boêmios de plantão', inspirando 'descontração' com 'restaurantes despojados' e 'bares e casas noturnas para todos os gostos' e 'qualquer hora'. A questão do 'divertimento' é ressaltada, bem como 'um tempero bem brasileiro' é mencionado. O Bairro da Liberdade, por sua vez, é identificado como um bairro étnico, ligado à herança oriental. Entre as atrações do bairro são citados os 'restaurantes e docerias típicas', as 'lojas de produtos orientais' e eventos associados às culturas chinesa e japonesa (festas em que o elemento gastronômico é um atrativo, embora esta informação não seja incluída).

O item "São Paulo por regiões" apresenta uma breve descrição de cada região e indica os principais atrativos daquele entorno. O quadro 6 
apresenta as menções à gastronomia por cada região:

\section{QUADRO 6 - Região Paulista e Ibirapuera}

\begin{tabular}{|c|c|c|}
\hline & Reqião & Mencão à gastronomia \\
\hline \multirow[t]{4}{*}{1} & \multirow[t]{4}{*}{$\begin{array}{l}\text { Paulista \& } \\
\text { Ibirapuera }\end{array}$} & $\begin{array}{l}\text { Rua Augusta: "Ela divide- se em duas } \\
\text { partes. Uma [...] possui várias opções } \\
\text { de lojas, restaurantes e cafés. Já a } \\
\text { outra [...] é um verdadeiro recanto de } \\
\text { bares e baladas ecléticas que atraem } \\
\text { um público variado" (p.43). }\end{array}$ \\
\hline & & $\begin{array}{l}\text { Rua Oscar Freire: "Além de estar } \\
\text { cercada de belíssimas vitrines, conta } \\
\text { também com maravilhosos } \\
\text { restaurantes, bares, cafeterias e } \\
\text { sorveterias, todos tão charmosos } \\
\text { quanto as lojas que os cercam, } \\
\text { tornando a experiência ainda mais } \\
\text { agradável" (p.43). }\end{array}$ \\
\hline & & $\begin{array}{l}\text { Itaú Cultural: "Possui também uma } \\
\text { Midiateca [...] além de um agradável } \\
\text { restaurante" (p.43). }\end{array}$ \\
\hline & & $\begin{array}{l}\text { Casa das Rosas: "Não deixe de } \\
\text { experimentar as delícias do Caffè } \\
\text { Ristoro Casa das Rosas, no jardim do } \\
\text { local" (p.43). }\end{array}$ \\
\hline
\end{tabular}

Fonte: O autor baseado em SP TURIS (2015).

A descrição geral da região destaca a importância financeira e cultural da avenida, um dos 'cartões postais da cidade' e uma área "[...] repleta de atrações turísticas, hotéis, cinemas, restaurantes e vida noturna" (p.40). São destacadas a diversidade da Rua Augusta, com um lado percebido como mais 'tradicional', com 'várias opções de lojas, restaurantes e cafés' e outro com 'bares e baladas ecléticas' que atraem um 'público variado'. A Rua Oscar Freire é mencionada por sua sofisticação, contando com 'charmosos' e 'maravilhosos restaurantes, bares, cafeterias e sorveterias'. O Itaú Cultural tem seu 'agradável restaurante' mencionado e a Casa das Rosas tem 'as delícias' de seu 'Café Ristoro Casa das Rosas'.

O quadro 7 apresenta as menções relacionadas ao bairro Centro:

\section{QUADRO 7 - Região Centro}

\begin{tabular}{|l|l|l|}
\hline & Região & Menção à gastronomia \\
\hline 1 & Centro & $\begin{array}{l}\text { Mosteiro de São Bento: "O local [...] abriga, } \\
\text { além da Basílica de N. S. Assunção, o } \\
\end{array}$ \\
& $\begin{array}{l}\text { mosteiro com cerca de 40 monges, } \\
\text { responsáveis também pela fabricação de } \\
\text { pães, bolos e doces produzidos com } \\
\text { receitas exclusivas e seculares, vendidos } \\
\text { na loja do local" (p.62). }\end{array}$ \\
\hline
\end{tabular}

\begin{tabular}{|l|l|}
\hline |l & $\begin{array}{l}\text { Edifício Copan: "Maior estrutura em } \\
\text { concreto armado do país, abriga mais de } \\
\text { dois mil moradores, além de lojas, } \\
\text { restaurantes e cafés" (p.66). }\end{array}$ \\
\hline $\begin{array}{l}\text { Edifício Itália / Circolo Italiano: "O edifício } \\
\text { abriga um teatro e um dos mais } \\
\text { tradicionais restaurantes da cidade, com } \\
\text { uma linda vista panorâmica da paisagem } \\
\text { urbana paulistana" (p.67). }\end{array}$ \\
$\begin{array}{l}\text { Mercado Municipal: "Encontre alimentos de } \\
\text { alta qualidade como frutas, carnes, } \\
\text { massas, doces, queijos, vinhos e um } \\
\text { espaço gastronômico com saborosos } \\
\text { pratos, como os tradicionais sanduíche de } \\
\text { mortadela e pastel de bacalhau" (p.72). }\end{array}$ \\
$\begin{array}{l}\text { Liberdade: "A cultura e a tradição dos } \\
\text { imigrantes são retratadas nas ruas } \\
\text { decoradas, no Museu da Imigração } \\
\text { Japonesa, nas lojas e restaurantes } \\
\text { orientais e na feira de artesanato" (p.72). }\end{array}$ \\
$\begin{array}{l}\text { Bixiga: "onde as tradições ainda são } \\
\text { mantidas ao ritmo da tarantela nas } \\
\text { padarias e cantinas, em sua maioria nas } \\
\text { Ruas Treze de Maio e Rui Barbosa" (p.73). }\end{array}$ \\
\hline
\end{tabular}

Na apresentação do Centro, o Bairro da Bela Vista é apresentado da seguinte forma "[...] outrora reduto italiano, as tradições ainda são mantidas nas cantinas, em sua maioria nas Ruas Treze de Maio e Rui Barbosa" (p.56). O Mosteiro de São Bento é lembrado pela 'fabricação de pães, bolos e doces' que são 'produzidos com receitas exclusivas e seculares'. O Edifício Itália é indicado por abrigar um dos 'mais tradicionais restaurantes da cidade', dotado com uma 'linda vista panorâmica da paisagem urbana paulistana' (observa-se que o nome do restaurante, Terraço Itália, não é mencionado, embora o salão do mesmo seja retratado em uma foto identificada na página 17). A menção ao Edifício Copan limita-se à presença de restaurantes e cafés em suas instalações.

Dois bairros são destacados sob a perspectiva étnica, mesmo que o termo não seja empregado. A Liberdade é novamente relacionada à 'cultura e a tradição dos imigrantes' orientais que se tornam evidentes nos restaurantes e na feira de artesanato (que também possui barracas de comida, embora não sejam mencionadas). O Bixiga por sua vez é descrito como 'bairro italiano' que mantém suas 'tradições' nas 'padarias e cantinas'. Já o mercado municipal é novamente colocado individualmente em evidência, descrito como um local onde se pode 
encontrar 'alimentos de alta qualidade' e um 'espaço gastronômico' com 'saborosos pratos' e onde se pode degustar os 'tradicionais' 'sanduíche de mortadela' e 'pastel de bacalhau'.

Verifica-se apenas uma menção gastronômica relacionada à região formada pelo Morumbi e Butantã, onde a presença da gastronomia se limita à indicação da possibilidade de 'saborear um chá à moda inglesa' no 'amplo jardim' da Fundação Maria Luisa e Oscar Americano. A região de Santana, Pacaembu e Higienópolis recebe apenas duas indicações gastronômicas: a feira de produtos orgânicos realizada no Parque da Água Branca e os "vários estabelecimentos comerciais, entre restaurantes, lojas, bares, padaria [sic] [...]" que existem no entorno da Praça Vilaboim.

\section{QUADRO 8 - Região Pinheiros e Vila Madalena}

\begin{tabular}{|c|c|c|}
\hline & Região & Menção à gastronomia \\
\hline \multirow[t]{5}{*}{1} & \multirow[t]{5}{*}{$\begin{array}{l}\text { Pinheiros } \\
\text { e } \\
\text { Vila } \\
\text { Madalena }\end{array}$} & $\begin{array}{l}\text { CEAGESP: "Terceiro maior mercado } \\
\text { atacadista do mundo e primeiro da } \\
\text { América Latina, a Companhia de } \\
\text { Entrepostos e Armazéns Gerais de } \\
\text { São Paulo (Ceagesp) é conhecida } \\
\text { pelas feiras de flores, barracas de } \\
\text { comidas e festivais de sopas que } \\
\text { organiza. É um grande centro de } \\
\text { abastecimento, onde se vendem } \\
\text { legumes, frutas, verduras, flores e } \\
\text { pescados". }\end{array}$ \\
\hline & & $\begin{array}{l}\text { Instituto Tomie Ohtake "Reúne oito } \\
\text { salas de exposição [...], livraria, café e } \\
\text { restaurante". }\end{array}$ \\
\hline & & $\begin{array}{l}\text { Bares e Restaurantes "A Vila } \\
\text { Madalena, ou Vila Madá para os mais } \\
\text { íntimos, é repleta de bares para todos } \\
\text { os gostos, desde botecos clássicos, } \\
\text { passando por aqueles que reúnem } \\
\text { jornalistas, aficionados por futebol, } \\
\text { amantes da música ao vivo, até os } \\
\text { voltados para o público GLS. Tudo } \\
\text { isso concentrado principalmente entre } \\
\text { as ruas Mourato Coelho, Fradique } \\
\text { Coutinho, Aspicuelta, Wisard, Wirassol". } \\
\text { Harmonia, Fidalga, Delfina e Girasolate }\end{array}$ \\
\hline & & $\begin{array}{l}\text { Praça Benedito Calixto: "A praça } \\
\text { possui ótimos bares e restaurantes e } \\
\text { também é conhecida pelas } \\
\text { apresentações de chorinho". }\end{array}$ \\
\hline & & $\begin{array}{l}\text { Museu da Casa Brasileira: "Nele fica } \\
\text { um restaurante de comida brasileira } \\
\text { com uma bela vista para os jardins do } \\
\text { museu". }\end{array}$ \\
\hline
\end{tabular}

Fonte: O autor baseado em SP TURIS (2015).

O descritivo geral indica que "a Vila Madalena é caracterizada pela boemia. Oferece uma diversidade de bares, restaurantes, ateliês, galerias de arte e locais para se divertir e é uma das regiões mais animadas da cidade [...] Vizinho a ela está Pinheiros, um bairro com bons restaurantes e compras interessantes". O Instituto Tomie Ohtake, a Praça Benedito Calixto e o Museu da Casa Brasileira são mencionados a partir dos estabelecimentos que Ihe são anexos. O Instituto conta com 'café' e 'restaurante'; a Praça com 'ótimos bares e restaurantes' e o Museu com 'um restaurante de comida brasileira' que possui uma 'bela vista para os jardins do museu'. O item Bares e Restaurantes novamente destaca a Vila Madalena, que é descrita como 'repleta de bares para todos os gostos', tem sua variedade comentada e as ruas que concentram o maior número de estabelecimentos indicadas.

A apresentação geral da região 'Vila Mariana e Ipiranga' indica que "[...] os turistas mais agitados encontram diversão em bares, restaurantes ou casas de shows", mas não realiza nenhuma menção a um elemento gastronômico. As regiões 'Zona Leste' e 'Pólo de Ecoturismo' não apresentam nenhuma menção.

\section{Análise geral - dos atrativos gastronômicos apresentados no Guia da Cidade}

Os elementos gastronômicos indicados no Guia da Cidade reforçam a ideia de uma cidade marcada pela diversidade e dinamicidade. A figura 1 apresenta uma nuvem com os adjetivos utilizados para qualificar estes elementos, dando destaque para os mais mencionados: 
FIGURA 1 - Qualitativos atribuídos aos elementos gastronômicos no Guia da Cidade

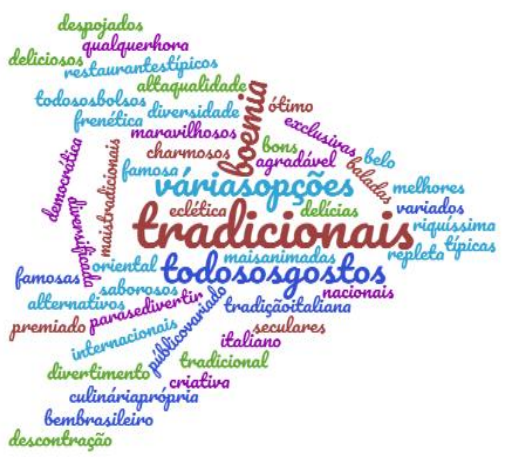

Fonte: o autor baseado em SPTURIS (2015).

Verifica-se 0 destaque para a noção de tradição, mas também a presença de vários qualitativos que indicam 'várias opções', como 'eclética', 'todos os gostos', 'diversificada' e ideias correlatas. A palavra 'democrática' é inclusive utilizada evidenciar o potencial que São Paulo tem de satisfazer diferentes perfis de gosto e padrões de consumo.

A figura 2 extrapola a figura 1 e apresenta uma nuvem criada com todas as menções relacionadas à gastronomia encontradas no Guia:

\section{FIGURA 2 - Menções a elementos gastronômicos encontrado no Guia da Cidade}

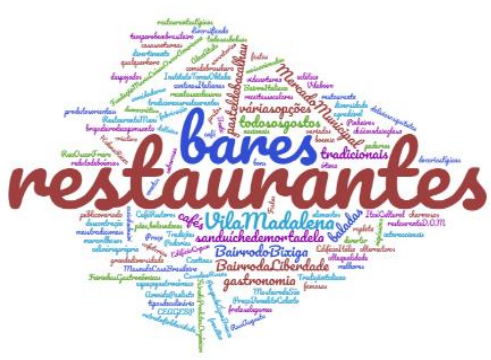

Fonte: a autora a partir de SPTURIS (2015).

Observa-se que o maior número de citações diz respeito aos termos 'restaurantes' e 'bares'. O volume e a diversidade destes estabelecimentos são mencionados em distintos momentos do Guia, evidenciando que o conjunto volumoso e diversificado de empreendimentos é percebido como uma marca e um diferencial de São Paulo, reforçando a ideia de 'capital gastronômica' indicada anteriormente. Contudo, a maior parte das indicações se dá de forma genérica, sendo apontados nominalmente apenas alguns elementos, como indica a figura 3 :

FIGURA 3:

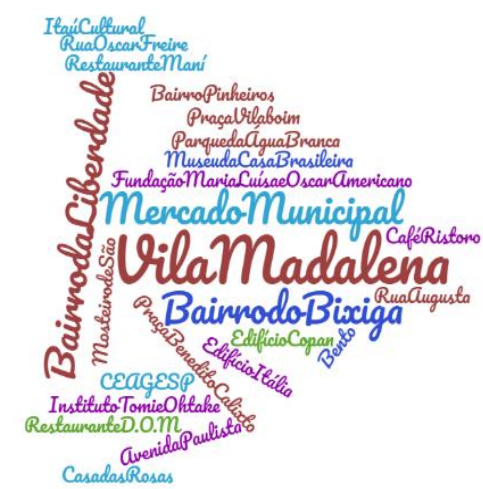

Fonte: o autor baseado em SPTURIS (2015).

Dentre os elementos nominados, o Mercado Municipal é o grande destaque. Sua variedade de produtos, a diversidade de restaurantes e até mesmo os detalhes arquitetônicos são apontados, bem como são associadas a ele as duas iguarias mais mencionadas no Guia. Na sequência o destaque é dado para o Bairro Vila Madalena, indicado como o principal núcleo da diversão noturna da cidade. Os bairros Bixiga e Liberdade também são destacados a partir de suas heranças étnicas e pela possibilidade de degustar ali iguarias trazidas e popularizadas por imigrantes italianos e japoneses, respectivamente.

Nota-se que em muitos dos lugares citados como a Casa das Rosas, o Itaú Cultural, o Edifício Copan, a Fundação Maria Luisa e Oscar Americano e o Instituto Tomie Ohtake -a oferta dealimentação constitui um serviço que agrega valor ao atrativo e que desempenha apenas um papel complementar.

Merece comentário específico as iguarias mencionadas no Guia. Embora sejam citados os termos 'culinária própria' e 'tempero bem brasileiro', apenas quatro iguarias são mencionadas nominalmente: coxinha de siri, brigadeiro de capim 
santo, pastel de bacalhau e sanduíche de mortadela. Deve-se observar que coxinha de siri e brigadeiro de capim santo não são representativos do que é produzido e degustado usualmente na capital. Já o pastel de bacalhau e o sanduíche de mortadela, citados três vezes cada um, são iguarias icônicas do Mercado Municipal e são mencionados sempre relacionados a ele.

Recuperando a categorização de atrativos gastronômicos proposta por Gimenes-Minasse (2014), verifica-se que o Guia da Cidade inclui atrações pertencentes a quatro categorias:

a) Estabelecimentos de alimentação fora do lar: como já mencionado, há um amplo destaque para a diversidade e o volume dos bares, restaurantes, casas noturnas, cafés e padarias espalhados pela cidade. Bem como algumas regiões são diretamente associadas a um perfil de estabelecimentos (como é o caso da vida noturna, diretamente relacionada à Vila Madalena e à Rua Augusta) ou um tipo de cozinha (como é o caso dos Bairros do Bixiga e da Liberdade). Contudo são citados nominalmente apenas o Caffé Ristoro (Casa das Rosas), o Restaurante D.O.M. e o Restaurante Maní, sendo estes dois últimos expoentes da alta gastronomia de São Paulo, com acesso restrito diante de suas respectivas capacidades de atendimento e ao alto ticket médio per capita.

b) Pratos e produtos típicos: Embora sejam encontradas menções a 'culinária própria', 'culinária nacional' e 'tempero bem brasileiro, as únicas iguarias citadas que podem ser consideradas representativas da cidade são o bolinho de bacalhau e o sanduíche de mortadela.

c) Estabelecimentos de comercialização de produtos: a CEAGESP e o Mercado Municipal são mencionados, sendo este último percebido como o grande atrativo gastronômico da cidade de São Paulo.

d) Feiras livres, feiras gastronômicas e comida de rua: há menções sobre 'famosas Feirinhas Gastronômicas', 'comida de rua' e 'feira de orgânicos', mas apenas esta última menção recebe alguma especificação (é apenas indicado que ela ocorre no Parque da Água Branca).

Analisando 0 quadro geral dos dados levantados, verifica-se que o Guia da Cidade aborda elementos representativos da cena gastronômica de São Paulo, mas, em sua função de fazer uma apresentação geral da cidade em um número limitado de páginas, termina por omitir vários elementos igualmente representativos, como o destaque que poderia ser dado às feiras e festas gastronômicas. Observa-se, neste sentido, que o Guia em questão apresenta aspectos que reforçam a imagem de diversidade e dinamicidade da gastronomia paulistana, em reflexo à própria imagem que se deseja atribuir à cidade de São Paulo.

\section{Considerações finais}

A partir dos dados aqui apresentados verificase que a cena gastronômica ganha destaque na publicação Guia da Cidade, seja como serviço que agrega valor a outros atrativos, seja como atrativo turístico propriamente dito. A imagem gastronômica da cidade é trabalhada de forma a reforçar a imagem da própria cidade, descrita como 'dinâmica', 'eclética' e 'diversa'.

Do ponto de vista dos atrativos turísticos gastronômicos, os elementos que se destacam são o conjunto de bares, restaurantes e casas noturnas que a cidade possui e o Mercado Municipal. O grande lapso do Guia reside na menção às iguarias, tendo em vista que duas das quatro citadas não integram o cotidiano paulistano, o que apresenta ao leitor a uma informação equivocada.

Recuperando as características e funções de um guia turístico, tem-se que este tipo de publicação visa sintetizar e interpretar uma realidade ao visitante que a desconhece, parcialmente ou por completo. Ocorre então um processo de seleção em que atrativos e informações são privilegiados em detrimento de outros, dando destaque e reforçando a importância daqueles elementos que são eleitos. Tendo em vista a diversidade e o potencial turístico das inúmeras manifestações gastronômicas da 
cidade de São Paulo, uma solução viável para o desenvolvimento do segmento do turismo gastronômico seria a elaboração de um guia específico, que poderia integrar a já existente Série Roteiros Temáticos.

\section{Referências}

ABRASEL. Notícias. Disponível em: http://www.sp.abrasel.com.br/a-abrasel Acessado em:10.05.2017.

ABRESI. São Paulo capital mundial da gastronomia. $2014 . \quad$ Disponível em: http://www.abresi.com.br/realizacoes_capital_ mundial_da_gastronomia.htm Acesso em 20.abr. 2017 .

ALHEMOUD, Abdullah. ARMSTRONG, Ernest. Image of Tourism attractions in Kuwait. In: International Journal of Travel Research, v. 34(4), 1996, pp.76-80.

BARDIN, Laurence. Análise de conteúdo. Lisboa: Edições 70, 2006.

COOPER, Chris. FLETCHER, John. WANHILL, Stephen. SHEPERD, Richard. Turismo princípios e práticas. 2.ed., Bookman, Porto Alegre, 2002.

CSERGO, Julia. A emergência das cozinhas regionais. In: FLANDRIN, Jean Louis; MONTANARI, Massimo. História da alimentação. São Paulo: Estação Liberdade, 1998. p. 806-824

DE MORAIS, Luciana. Sabores de viagem: as culinárias regionais nos guias turísticos entre 1966 e 1983. In: Revista Rosa dos Ventos, Dossiê Turismo e Gastronomia, 4(3), jul-set, 2012, pp. 317-334.

ECHTNER, Chris. RITCHIE, John. The meaning and measurement of destination image. In: Journal of Tourism Studies, v. 2(2), 1991, pp. 2-12.

FAGLIARI, Gabriela Scuta. Turismo e alimentação: análises introdutórias. São Paulo: Roca, 2005.

GÂNDARA, José Manoel Gonçalves; GIMENES, Maria Henriqueta Sperandio Garcia; MASCARENHAS, Rubia. Reflexões sobre o turismo gastronômico na perspectiva da sociedade dos sonhos. In: PANOSSO NETTO, Alexandre; ANSARAH, Marília Gomes dos Reis. (org). Segmentação do mercado turístico: estudos, produtos e perspectivas. São Paulo: Manole, 2009, p. 179-194.

GIMENES-MINASSE, Maria Henriqueta. Atrativos gastronômicos da cidade de São Paulo: uma análise preliminar. In: Anais do Seminário ANPTUR, 2014. Disponível em: http://www.anptur.org.br/anptur/anais/v.10/Anai s/DCL5/026.pdf Acessado em: 15 abr.2017.

GUIA MICHELIN. Restaurantes Michelin Brasil. Disponível em: https://www.viamichelin.pt/web/Restaurantes/R estaurantes-Brasil Acessado em: 12.abr.2017.

HALL, C. Michael; SHARPLES, Liz. The consumption of experiences or the experience of consumption. An introduction to the tourism of taste. In: HALL, C. Michael; SHARPLES, Liz; MITCHELL, Richard; MACIONIS, Niki; CAMBOURNE, Brock. Food tourism around the world - development, management and markets. Oxford: Elsevier, 2003, p.1-24.

LOHMANN, Guilherme; PANOSSO NETTO, Alexandre. Teoria do Turismo. Aleph: São Paulo, 2008.

MATOS, Ana Cardoso; SANTOS, Maria Luísa F. N. Os guias de Turismo e a emergência do Turismo contemporâneo em Portugal (dos finais de século XIX às primeiras décadas do século XX). In: Scripta Nova - Revista Eletrónica de Geografía y Ciencias Sociales. Universidad de Barcelona, v.3, n. 167, jun.2004.

OBSERVATÓRIO DE TURISMO. Anuário 2015 - ano base 2014. Observatório de Turismo: São Paulo, 2015. Disponível em: http://www.observatoriodoturismo.com.br/pdf/A NUARIO_2015_BASE_2014.pdf Acessado em: 12.abr.2017.

RICHARDS, Greg. Gastronomy: an essential ingrediente in tourism production and consumption? In: HJALAGER, AnneMette.; RICHARDS, Greg. (org). Tourism and gastronomy. Oxford Routledge, 2002, p. 3-20.

SCHLÜTER, Regina. Turismo y patrimonio gastronómico - una perspectiva. Buenos Aires:CIET, 2006 (edição revisada e ampliada).

SPTURIS. Guia da Cidade. São Paulo: SPTuris, 2015. Disponível em: http://cidadedesaopaulo.com/download/ Acessado em: 10.abr.2017.

SPTURIS. Download de materiais. Disponível em: http://cidadedesaopaulo.com/download/ Acessado em: 10.abr.2017. 